\title{
OS NOVOS CONTORNOS DA LOUCURA NO ESPAÇO URBANO CONTEMPORÂNEO
}

\author{
Carolina Santos Nakadomari (Psicologia - UEL) \\ Profa. Dra. Sonia Regina Vargas Mansano (Orientadora)
}

\section{RESUMO}

A presente pesquisa tem por objetivo compreender a relação entre a loucura e os modos de subjetivação atualizados nas cidades, analisando como a organização do espaço urbano, permeada pelas regulamentações intrínsecas ao modelo econômico vigente, interfere na despotencialização e adoecimento psíquico da população. $O$ estudo baseiase na análise da loucura em uma perspectiva histórica, dando ênfase em suas reverberações e reconfigurações no meio social. Abordamos a produção da loucura e seus efeitos psicossociais a partir do conjunto de normas padronizadoras que diferenciam o indivíduo dito normal daquele considerado patológico, distribuindo a população entre esses dois extremos. Verificamos, no decorrer do estudo, que a organização da vida nas cidades, caracterizada pela velocidade, produtividade, consumo, competitividade e individualização, coopera para dar novos contornos à loucura, reconfigurando sua incidência. Nesse sentido, a pesquisa buscou identificar os novos contornos do que é considerado atualmente "loucura" e como essa noção vem ganhando espaço de expressão no cotidiano das cidades, sendo enunciada em situações outrora localizadas fora desse campo. Como conclusão parcial, o estudo elucida onde e de que quais maneiras as adversidades da vida urbana ganha contornos afetivamente insustentáveis, colocando a população urbana em um ritmo frenético e enlouquecedor de produção, deslocamento e consumo.

Palavras-chave: loucura, subjetividade, espaço urbano.

\section{INTRODUÇÃO}

Da alienação ao delírio; da insanidade ao desvario; da insensatez à excentricidade, a noção de loucura trilha diversos caminhos, variando suas definições historicamente. Não se consolida e nem se restringe, portanto, unicamente a uma determinação fechada pelo fato de ser, desde os primórdios até o presente mais imediato, o cerne de um incômodo humano no que toca a estimada e privilegiada condição de "superioridade": a razão. Etimologicamente, segundo o Grande Dicionário Etimológico - prosódico da língua portuguesa de Bueno (1966) - encontra-se a seguinte definição da palavra 'louco': “adj. Insensato, demente, doido, maníaco, alienado, mentecapto, pessoa que sofre das faculdades mentais, que não tem bom juízo". A raiz do termo é assim descrita:

A existência deste adjetivo unicamente na Península Ibérica, em português e espanhol, inexistente em outras línguas românicas, exige étimo próprio desta região. Por êste fato, entre todas as hipóteses apresentadas pelos etimologistas, a única plausível é a do ár. Láuqa, tonto, bobo, fátuo. A forma primeira foi, pois, a feminina louca sôbre a 


\section{SEMINÁRIO DE PESQUISA EM CIÊNCIAS HUMANAS - SEPECH \\ Humanidades, Estado e desafios didático-científicos \\ Londrina, 27 a 29 de julho de 2016}

qual se fêz o masc. louco. Isto não é dificuldade alguma porque outros casos semelhantes existem, v. g. o de sandeu derivado fem. sandia e este forma do ár. sandia, melancia, com cujo tamanho foi comparado o crânio do bobo, do louco (BUENO, 1966, p. 2221).

Cabe considerar que o uso dessa palavra também é muito frequente no cotidiano, sendo valorada e reestruturada em diversos tipos de discursos a partir de perspectivas variadas. Seu uso percorre desde a área da saúde, responsável pela apropriação de termos específicos para designar pontualidades no âmbito de suas especialidades, até ser contemplada nas conversas informais, sendo atrelada, nesse caso, aos traços culturais de expressão.

É corriqueira a utilização dos termos loucura e louco em diversos contextos e com significados diferentes, sendo utilizados, de maneira geral, em conversas informais como um adjetivo pejorativo. Mas também, atualmente, essa expressão pode ser atribuída àqueles que excedem os limites sociais, de modo que as experiências vividas transpassam os moldes instituídos, sendo consideradas descabidas.

A noção de louco, no que tange à relação com o doente mental, foi apropriada com uma conotação depreciativa, de maldizer àqueles acometidos pela loucura e que, em sua condição alucinada, perturbavam uma suposta "harmonia" entre os lúcidos. Pode-se notar que no mesmo sentido, muitos outros sinônimos desdenhosos foram criados a partir da figura do louco, como por exemplo, doido, maluco, tonto, lunático e alienado.

A utilização do termo também pode ser encontrada quando dirigida ao sujeito que exacerba a expressão de seus afetos, sejam eles avaliados como bons ou ruins. Tomado pelo exagero, tem-se o "louco de amor", "louco de ódio" ou "louco de tristeza". Cada qual traz como atributo da loucura o excesso, a impulsividade animalesca que leva a cometer atos de loucura, supostamente motivados pelo ímpeto de um corpo tomado de insanidade. Nesse caso, nota-se uma variação na significação da palavra, tendo em vista que já não mais se refere aos acometidos por uma "doença", mas estende-se a todos e quaisquer sujeitos atravessados por emoções latentes e expressas de modo exagerado.

Tomando em consideração esse amplo leque se significações socialmente atribuídos à palavra loucura, buscou-se, nesta investigação, identificar e compreender a relação entre a loucura e os modos de subjetivação atualizados nas cidades. Para tanto, investiga-se primeiramente a noção de loucura em uma perspectiva histórica. Em seguida, problematiza-se como as regulamentações intrínsecas ao modelo econômico capitalista vigente, interferem na despotencialização e adoecimento psíquico da população, dando espaço para ressignificação e ampliação da ideia de loucura.

\section{A LOUCURA EM UMA PERSPECTIVA HISTÓRICA}

Atualmente, seguindo o ritmo de vida definido pela lógica do sistema econômico vigente que prioriza a busca pelo acúmulo de bens e de capital, vê-se, via de regra, sujeitos que tendem à apatia que reproduzem valores e padrões estipulados pelas metas a serem alcançadas nas diferentes esferas da existência. Tais sujeitos acumulam-se no meio urbano, produzindo dinheiro e riqueza, consumindo e sendo consumidos. Aquelas 


\section{SEMINÁRIO DE PESQUISA EM CIÊNCIAS HUMANAS - SEPECH \\ Humanidades, Estado e desafios didático-científicos \\ Londrina, 27 a 29 de julho de 2016}

dimensões da vida que porventura se afastam minimamente dessa "normalidade" estabelecida e amplamente naturalizada estão fadadas a ser criticadas, podendo, sob o ponto de vista produtivista, ser classificadas como loucura.

O louco dos dias atuais é aquele que ultrapassa o modo de vida ordenado e automatizado, que vive em uma dinâmica diferente do ritmo de produção e do capital, sendo desqualificado pelos tidos como "normais". Comumente, uma caracterização recorrente do louco refere-se àquele que não segue o mesmo ritmo frenético de produção que a maioria; aquele que se permite valorizar outras dimensões da vida, diferentes da mercadológica; aquele que estima as experiências muito mais do que os rendimentos e a produtividade.

Diante desse quadro urbano, cabe questionar: Seria "normal" manter a existência em um ritmo acelerado de produção? Por que os que se afastam do vertiginoso ciclo de produção capitalista são denominados loucos? Para compreender como a noção de loucura é usada e experimentada no contexto das cidades, faz-se necessário uma análise sobre a noção de normalidade e seus desdobramentos sócio-históricos. Sendo assim, considera-se que o estudo sobre a loucura tome em análise os modos de subjetivação mais normatizados e naturalizados como "normais". Partimos do pressuposto de que a noção de loucura hoje é indissociável dos modos de vida atualizados nas cidades contemporâneas e possui conformidade própria, sendo necessário analisá-la na interface entre o que se atribui socialmente tanto à noção de normalidade quanto a de loucura.

O louco tende a ser negado ou excluído por parte daqueles que se consideram em plena iluminação mental. A presença viva da loucura no cotidiano é, invariavelmente, um desconforto às mentes sadias, haja visto ser a oposição direta da definição normalizadora dos indivíduos. Tal desconforto não ocorre por mero desapreço, mas sim pela necessidade social de repressão e controle do desviante e de sua conduta que transpassa a ordem instituída.

Foucault, em seu curso Os Anormais (2001), elucida como a configuração repressora operada contra o louco é produto da compreensão do que se considera normal em cada tempo histórico. Tal compreensão envolve o fato de as normas sociais predominantes terem por base uma linha padrão de direcionamento dos modos de vida, pela qual "classificam-se" os sujeitos quanto ao seu comportamento de afastamento ou concordâncias em relação ao que é determinado como norma socialmente compartilhada. Deste modo, cada tempo histórico, em suas particularidades, elabora um constructo de práticas, valores e regras determinadas que instituem os preceito de normalidade. Sendo assim, as características atribuídas à loucura variam, desconfigurando-se e reorganizando-se de acordo com cada delineamento temporal.

Porém, na análise de Foucault sobre os anormais, a insanidade, desviante da normalidade, não foi relacionada somente aos afetados por distúrbios mentais, mas a todos os excluídos socialmente que transgrediam as normas culturais definidoras da normalidade. Por serem numerosos, a categoria de "loucos" englobava os bandidos, homossexuais, prostitutas, moradores de rua e tantos outros que resistiam às normas. Foucault, na obra História da Loucura, salienta a normalização impositiva como reflexo da conjectura social:

O que é designado nessas fórmulas não são doenças, mas formas de loucura que seriam percebidas como o extremo de defeitos. Como se, no internamento, a sensibilidade à loucura não fosse autônoma, mas 


\section{SEMINÁRIO DE PESQUISA EM CIÊNCIAS HUMANAS - SEPECH \\ Humanidades, Estado e desafios didático-científicos \\ Londrina, 27 a 29 de julho de 2016}

ligada a uma certa ordem moral onde ela só aparece a título de perturbação. Lendo-se todas essas menções que, nos registros, são colocadas diante do nome dos insanos, tem-se a impressão de que se está ainda no mundo de Brant e Erasmo um mundo onde a loucura conduz toda uma ronda dos defeitos, a dança insana das vidas imorais (FOUCAULT, 2008, p. 136).

A conotação atribuída ao louco como potencial "ameaça" àquela parcela da população considerada "normal" demandava medidas de proteção da integridade civil coletiva, as quais deveriam dar ao sujeito aberrante o tratamento apropriado, considerando o seu isolamento como medida primeira. O sujeito louco seria levado, sem prévio aviso ou escolha, para espaços de reclusão, sendo colocado na convivência de seus "semelhantes". Esse internamento forçado é discutido por Passos e Beato quando consideram:

Internando-se os loucos (ainda não individualizados como tais) em hospitais gerais, junto com todo tipo de indesejáveis sociais, o grande gesto do internamento foi produzindo uma mudança fundamental nas percepções anteriores da loucura (míticas, religiosas etc.) como desrazão, lançando as bases de um novo tipo de domínio - o silenciamento e a segregação do louco do convívio social (PASSOS; BEATO, 2005, p. 145).

O louco incluído nas instituições, agora invisível a quem lhe condenava, se viu forçado a renunciar sua vida em favor de um corpo desabitado, mantido sob a repressão de autoridades arbitrárias e ficando distante do convívio no espaço urbano. De acordo com Goffman (2013), as chamadas instituições totais, dirigidas aos loucos, mantinham esses sujeitos praticamente encarcerados. Tais instituições apossam-se deles e transfiguram-nos em mais um louco, como os outros que o cercam, desapropriando-os tanto de pertences pessoais, quanto de características físicas e do poder de decidir por si. Dentro das instituições totais abre-se mão do eu. Nas palavras do autor: "A barreira que as instituições totais colocam entre o internado e o mundo externo assinala a primeira mutilação do eu" (GOFFMAN, 2013, p. 24), sendo essa seguida por infinitas outras mutilações, que desconfiguram a história subjetiva e comprometeram a integridade física. Considerando, então, a concepção da loucura por sua conformação sóciohistórica, quais são os efeitos na contemporaneidade? Na organização do espaço urbano e na vida dentro dos grandes cidades?

\section{A LOUCURA NO ESPAÇO URBANO}

A retirada dos sujeitos caracterizados como loucos do espaço urbano compartilhado foi a forma mais eficaz de conter tamanho incômodo gerado pela diferença, agora avaliada como insanidade, impedindo o convívio social livre, seus movimentos e sua autonomia. Assim, a contenção do louco tinha como uma premissa a garantia que esse não interferiria na condução das vidas normais atualizadas nas cidades e em suas capacidades produtivas. 


\section{SEMINÁRIO DE PESQUISA EM CIÊNCIAS HUMANAS - SEPECH \\ Humanidades, Estado e desafios didático-científicos \\ Londrina, 27 a 29 de julho de 2016}

A rejeição à loucura, como estamos demonstrando, diz respeito ao afastamento de corpos considerados inúteis, uma vez que não se enquadram ao acelerado sistema de produção capitalista, sendo então categorizados como improdutivos. Acompanhando a análise contextualizada de Foucault, pode-se dizer que o "louco" passou a representar na história recente um sujeito desnecessário para a conformação produtiva do meio no qual ele vive, sendo tido como um empecilho ou, em uma vertente mais excludente, como um "perigo" social.

Essa noção de rendimento e utilidade está ligada ao modelo econômico capitalista, o qual está mais acentuado no sentido de valorizar a eficiência lucrativa nos centros urbanos. Desde a segunda metade do século XX, de maneira mais acentuada, as cidades estão mais imersas na lógica de consumo e produção, não tendo espaço para abarcar o que se desvia disso, incluindo aqui a loucura. $\mathrm{O}$ indivíduo considerado louco encontra-se à margem do convívio social, sendo excluído por não acompanhar a velocidade requerida para que as cidades sigam em franco desenvolvimento.

Segundo Harvey (2013, p. 28) "ao refazer as cidades refazemos a nós mesmos". Isso evidencia que os modos de existência urbanos são atravessados pelos modos de produção urbanos, de forma que um depende do outro para se manter. Como a propulsão dos indivíduos nas cidades está diretamente ligada ao potencial de produção e/ou consumo, o esforço para alcançá-lo faz com que suas vidas se direcionem à produção massiva, naturalizada e distante de qualquer referência crítica. Portanto, viver em uma cidade implica dedica tempo, força e aspirações à manutenção do sistema, ainda que isso ganhe contornos insanos.

As cidades contemporâneas crescem vertiginosamente, mas esse crescimento é calculado majoritariamente em relação à expansão do capital, ou seja, o quanto cresce em território, o quanto totaliza em patrimônio, quantos novos investimentos são efetuados e quantos novos habitantes entram a cada ano no ciclo de produção. Tais mensurações dizem respeito ao percentual lucrativo das cidades. Guattari (1992) em seu livro "Caosmose" mostra como essa lógica de produção é insustentável em suas bases, uma vez que exige, do meio ambiente e dos indivíduos, mais do que se pode extrair. Isso serve para manter uma dinâmica que é no mínimo autodestrutiva. Daí a urgência colocada pelo autor de repensar criticamente os problemas atuais gerados por esta ordem econômica. Pelas palavras do autor, na situação em que as cidades se encontram "Ou a humanidade [...] reinventará seu devir urbano, ou será condenada a perecer sob o peso de seu próprio imobilismo, que ameaça atualmente torná-la impotente face aos extraordinários desafios com os quais a história a confronta" (GUATTARI, 1992, p. 178).

$\mathrm{Na}$ mesma medida em que as cidades se desenvolvem em seu aspecto econômico, as complicações sociais resultantes do crescimento descontrolado também se acentuam. Os problemas básicos vividos pelos cidadãos no cotidiano indicam a gravidade da situação em que se encontram as cidades. $\mathrm{O}$ que se vê como normalizado nesse modo de vida urbano é, em grande parte, o que mais oferece risco a quem se sujeita a viver no espaço das grandes cidades: conduzir a vida orientado pela lógica do acúmulo implica adoecimento, incluindo o emocional.

No início desta investigação, vimos que a tipificação do louco o definia como alguém desabilitado das capacidades necessárias para adentrar os meios de produtividade contemporâneos. Mesmo sendo parte desse meio social, o sujeito se torna um incomodo à normalidade em sua condição não rentável em relação às metas e 


\section{SEMINÁRIO DE PESQUISA EM CIÊNCIAS HUMANAS - SEPECH \\ Humanidades, Estado e desafios didático-científicos \\ Londrina, 27 a 29 de julho de 2016}

moldes econômicos. Porém, quando analisamos as cidades contemporâneas regidas pelo modelo econômico baseados em produção e consumo, o modo de vida definido como normal tem ajudado a construir, em nossa percepção, uma espécie de "loucura urbana cotidiana". Tal loucura urbana tende a reduzir as possibilidades de vida do cidadão, limitando-o à lógica do capital. Essa limitação dissemina a ideia de progresso e desenvolvimento como fundamentos de suas estruturas, colocando ao sujeito a obrigatoriedade de aderir ao ritmo, por vezes patológico e estressante, de manutenção da produção, com foco no lucro, nas metas, no controle e na expansão financeira e pessoal.

Em nossa análise, é estabelecida hoje uma relação direta entre o modo de vida tido como "normal" (caracterizado como produtivo e apto para aderir aos valores capitalistas) e a organização do espaço urbano (desenhado para dar fluidez à exclusiva produção). Com isso, essa organização abre espaço para o surgimento de novos contornos para a noção de "loucura", acentuando os traços de individualismo, a competição cega, a desconfiança generalizada, o controle recíproco, a violência gratuita e o medo da diferença.

A partir dessa constatação, nota-se como se tornou estratégico, sob o ponto de vista da produção, sobrepor a noção de normalidade à de loucura, haja vista que o dito normal é "aceitável" no cotidiano dos centros urbanos, ainda que possa explicitar características doentias. Partindo dessa perspectiva, questionamos o quanto de "patológico" e afetivamente insustentável se faz presente nos modos de viver urbanos que consideramos "normal". E onde está, afinal, o louco que tanto foi excluído? Não estaria ele entre os que são ávidos por lucro e que são, atualmente, ditos lúcidos e bem integrados no social?

\section{CONSIDERAÇÕES FINAIS}

As análises acerca da construção social da loucura e de sua reverberação nos modos de viver e organizar as cidades evidenciam uma tendência ao confronto entre o que é definido como normal e anormal, tendo como referência os valores produtivistas do capital ora em vigor.

Deste modo, quando se analisa a organização espacial, social e produtiva dos centros urbanos, nota-se a presença de múltiplas forças que concorrem para definição, e possível exclusão, daquele que é considerado louco. No que toca ao direcionamento dos indivíduos unicamente para a produção e o consumo, o louco agora é definido como improdutivo, ineficiente, incapaz ou preguiçoso. Tal concepção colabora para promover uma hostilidade e rejeição em relação àqueles que se afastam dos moldes estruturais do sistema econômico.

Porém, a análise aqui proposta indicou a necessidade de questionar se não são exatamente os modos de vida urbanos (com seu ritmo acelerado, seus objetivos lucrativos e a indisponibilidade do ócio) que favorecem o adoecimento, e mesmo o enlouquecimento da população. Esta última encontra-se praticamente conformada aos valores de produtividade e acúmulo, os quais são naturalizados como única forma de vida possível. O resultado desse empreendimento é visível nos corpos cansados e nas mentes fadigadas, que se mantém em um incessante ciclo patológico de produtividade.

Os novos contornos da loucura, marcados pela produtividade exacerbada, permeiam o urbano em sua mais consolidada e atual conjuntura social, onde os modos 


\section{SEMINÁRIO DE PESQUISA EM CIÊNCIAS HUMANAS - SEPECH \\ Humanidades, Estado e desafios didático-científicos \\ Londrina, 27 a 29 de julho de 2016}

de vida são atravessados estruturalmente pelas exigências mercadológicas e culminam na despotencialização dos indivíduos frente às demandas a serem cumpridas. Consideramos que essa adesão acrítica, em larga medida, favorece a manutenção de aspectos enlouquecedores que se tornaram as bases de regulação para uma vida normal a ser simplesmente seguida.

\section{REFERÊNCIAS}

BUENO, F. S. Grande dicionário etimológico - prosódio da língua portuguesa. 5 ed. São Paulo: Saraiva, 1966.

FOUCAULT, M. História da Loucura. Tradução de José Teixeira Coelho Neto. 8. ed. São Paulo: Perspectiva, 2008.

FOUCAULT, M. Os Anormais. Tradução de Eduardo Brandão. 1 ed. São Paulo: Martins Fontes, 2001.

GOFFMAN, E. Manicômios, Prisões e Conventos. Tradução de Dante Moreira Leite. 8 ed. São Paulo: Perspectiva, 2013.

GUATTARI, F. Caosmose um novo paradigma estético. Tradução Ana Lúcia de Oliveira e Lúcia Cláudia Leão. São Paulo: Editora 34, 2006.

MARICATO, E. [et al]. Cidades rebeldes: Passe livre e as manifestações que tomaram as ruas do Brasil. São Paulo: Boitempo, 2013.

PASSOS, I. C. F.; BEATO, M. S. F. Concepções e práticas sociais em torno da loucura: alcance e atualidade da História da Loucura de Foucault para investigações etnográficas. Psychê, São Paulo, v. VII, n.12, p.137 - 158, dez 2003. 